\title{
Editorial
}

\section{The Renaissance of the permanent establishments within the EC}

Helmut Becker, Deloitte \& Touche GmbH, Düsseldorf

With the exception of banks and insurance companies, currently only a few enterprises maintain bigger permanent establishments within the EC; most of the permanent establishments represent smaller units. Therefore the significance of such establishments was rather limited. This situation may change. There are three areas supporting such a conclusion.

First of all the OECD has been dealing with permanent establishments for some time. Committee 6 is dealing with the allocation of profits between the main office and the permanent establishment. Committee 1 is reconsidering the commentary of the OECD Model Treaty. Both might result in a new definition of a permanent establishment and new rules for the profit allocation. Apart from that the EC has just proposed a multilateral model agreement $^{1}$ for an arbitration procedure which includes the profit allocation between main office and permanent establishment. All this has already resulted in a higher significance of the problems concerning a permanent establishment.

Apart from that also the number of permanent establishments will increase and will very likely result in bigger entrepreneurial units. There is first the European Economic Interest Grouping $^{2}$ which is taxwise treated as a partnership. ${ }^{3}$ Therefore it constitutes a permanent establishment for its members resident in one EC country in the country in which it is created. Even more important is the merger directive ${ }^{4}$ which also covers corporate divisions.

If two corporations are merged across the border the merged company disappears as a legal unit, however, remains as entrepreneurial unit. Such unit represents a permanent establishment of the acquiring company in the former country of residence. That means that the disappearing corporation will be transformed into a permanent establishment. Something similar will happen in the case of a division. In such a case the existing property of a corporation will be split into two or more parts which are transferred to another corporation. Thereby the shareholders of the old corporation get shares of the absorbing corporation. If the absorbing corporation is located in another EC country once again the property attributed to it remains in the original country now representing a permanent establishment. It can be assumed that such kind of co-operations and transactions will increase. Therefore the number and the significance of the permanent establishments will increase, too.

However, there is a third area which will cause new permanent establishments. Most companies expect after the frontier-barriers will have disappeared in the course of Europe 92 that they are able to deliver their goods to any place within the EC within 24 hours. If this comes true the local warehouses in the different countries will be replaced by one central warehouse and the significance of the distribution companies within the different EC countries will be reduced. Therefore there is some likelihood that big dealers will insist on direct deliveries; of course, at lower prices. Such direct deliveries might result in visits from the home office to those dealers. If at this occasion orders are also collected this means taxwise that a dependent agent with the authority to conclude contracts-very likely regularly-makes use of said authority. All this meets the requirements of a permanent establishment. As such visits are performed with several dealers in different countries this may result in numerous permanent establishments.

1 Official Journal of the EC No.L $225 / 10$ as of 20 August 1990

2 Official Journal of the EC No. L $199 / 1$ as of 31 July 1985.

3 See letter of the German Ministry of Finance, 15 November 1988, Der Betrieb 1989, page 354.

4 Official Journal of the EC No. L $225 / 6$ as of 20 August 1990. 
Or another example: a common market requires a joint strategy and a more centralized management. Therefore the existing local management may be replaced or at least accompanied by a central management. As such harmonization is not combined with a harmonized tax law - the harmonized market will meet a not harmonized taxation - the central management will create a permanent establishment of the foreign business units. Those permanent establishments do not result from instruments directly targeted to a harmonized market as the merger directive. In spite of that the permanent establishments appear indirectly and as a side effect. Therefore a distinction could be made between a primary and a secondary effect both resulting in more permanent establishments than we had in the past.

Anyway, it can be foreseen that the number and the significance of the permanent establishments will increase; the permanent establishments are going to have a renaissance. The tax community therefore would be well advised to consider such development in time.

\section{Good news for those involved in financial services ...}

\section{AMSTERDAM FINANCIAL SERIES}

\section{Comprehensive guide}

Amsterdam Financial Series provides both practitioners and academics with a comprehensive guide to the impact of European Community regulation on financial services, such as Banking, Insurance, Investment, Accountancy, Legal and Financial Consultancy and Stock Exchange.

\section{Expertise}

This unique new series has been produced under authority of general editor Martijn van Empel with the assistance of a number of experts who have been personally involved in the gestation of this intricate but fascinating field of law. It has been published under the responsibility of the Europa Institute of the University of Amsterdam, and under the aegis of "Amsterdam Financial Centre".

\section{Practical set-up}

Amsterdam Financial Series is divided into four parts. The first volumes regroup all materials and cases which are relevant to the subject. Other volumes will consist of commentaries on the various subjects. New develop-ments can be incorporated on a regular basis by means of future supplements.

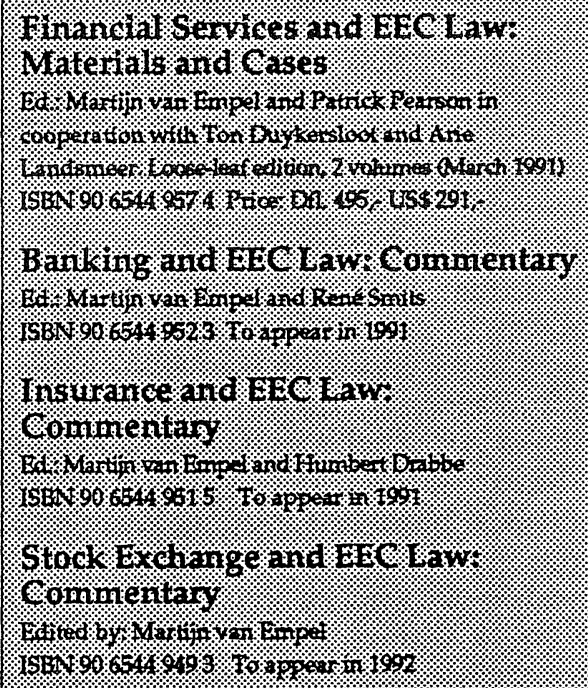

